\title{
Mesoscale Moisture Transport by the Low-Level Jet during the IHOP Field Experiment
}

\author{
Edward I. Tollerud, ${ }^{*}$ Fernando Caracena,* Steven E. Koch,* Brian D. Jamison,*,+ \\ R. Michael Hardesty,* Brandi J. McCarty,*,\# Christoph Kiemle, ${ }^{\circ}$ Randall S. Collander, $*,+$ \\ Diana L. Bartels,* Steven Albers,*,+ Brent Shaw, \& Daniel L. Birkenheuer,* and \\ W. Alan Brewer* \\ *NOAA/Earth System Research Laboratory, Boulder, Colorado \\ + Cooperative Institute for Research in the Atmosphere, Fort Collins, Colorado \\ \# Cooperative Institute for Research in the Environmental Sciences, Boulder, Colorado \\ @ German Aerospace Center (DLR), Oberpfaffenhofen, Germany \\ $\&$ Weather Decision Technologies, Inc., Norman, Oklahoma
}

(Manuscript received 16 October 2007, in final form 1 February 2008)

\begin{abstract}
Previous studies of the low-level jet (LLJ) over the central Great Plains of the United States have been unable to determine the role that mesoscale and smaller circulations play in the transport of moisture. To address this issue, two aircraft missions during the International $\mathrm{H}_{2} \mathrm{O}$ Project (IHOP_2002) were designed to observe closely a well-developed LLJ over the Great Plains (primarily Oklahoma and Kansas) with multiple observation platforms. In addition to standard operational platforms (most important, radiosondes and profilers) to provide the large-scale setting, dropsondes released from the aircraft at 55-km intervals and a pair of onboard lidar instruments-High Resolution Doppler Lidar (HRDL) for wind and differential absorption lidar (DIAL) for moisture-observed the moisture transport in the LLJ at greater resolution. Using these observations, the authors describe the multiscalar structure of the LLJ and then focus attention on the bulk properties and effects of scales of motion by computing moisture fluxes through cross sections that bracket the LLJ. From these computations, the Reynolds averages within the cross sections can be computed. This allow an estimate to be made of the bulk effect of integrated estimates of the contribution of small-scale (mesoscale to convective scale) circulations to the overall transport. The performance of the Weather Research and Forecasting (WRF) Model in forecasting the intensity and evolution of the LLJ for this case is briefly examined.
\end{abstract}

\section{Introduction}

Previous studies of the low-level jet (LLJ) have helped to establish its role as the major conveyor of low-level moisture from the Gulf of Mexico into the central United States (Stensrud 1996; Higgins et al. 1996). Higgins et al. (1997) estimate that the contribution of the LLJ to low-level moisture transport over the central plains is almost $50 \%$ above average non-LLJ values. A major factor in the LLJ contribution to central plains precipitation is the relationship between the LLJ and development of mesoscale convective complexes (MCCs; Maddox 1983; Augustine and Caracena

Corresponding author address: Edward I. Tollerud, Earth System Research Laboratory, 325 Broadway, Boulder, CO 80305. E-mail: edward.tollerud@noaa.gov
1994). Indeed, Fritsch et al. (1986) estimate that MCCs might be directly responsible for one third or more of all warm season precipitation in the central United States. Anderson and Arritt (1998) describe the relationship among intense MCC development, synoptic setting, and the extreme precipitation that occurred in the flood-plagued northern Mississippi basin during the spring and summer of 1993.

Unfortunately, because of inadequate spatial and temporal resolution, the existing radiosonde network in the United States is not well suited to capture the LLJ. Climatological studies using radiosondes have helped to clarify LLJ mechanisms (e.g., Bonner 1968), but because they are often limited to a single observation within each LLJ sampled they cannot describe horizontal wind or thermodynamic gradients with precision. More recent studies employing the National Oceanic 
and Atmospheric Administration (NOAA) wind profiler network address the time resolution issue (Mitchell et al. 1995; Anderson and Arritt 2001). However, these studies are affected by the fact that wind profilers often miss the very shallow LLJs that peak below the lowest observation gate, which can be $500 \mathrm{~m}$ or more above the ground (Whiteman et al. 1997; Daniel et al. 1999).

The use of dropsondes and lidar wind data in focused LLJ studies both inside and outside the domain of the central United States has proven very useful (Banta et al. 2002; Ralph et al. 2005). However, to date there have been no studies that combine these different measurements to describe the detailed horizontal mesoscale and submesoscale structure of moisture transport within the central plains LLJs.

In the numerical modeling and analysis arenas, questions persist about the ability of existing operational models to adequately predict LLJ moisture transports. For instance, Anderson and Arritt (2001) conclude that NCEP-NCAR reanalysis fields significantly underestimate the frequency of strong LLJs. In part this may result from the relatively coarse horizontal resolution of the reanalysis $\left(2.5^{\circ} \times 2.5^{\circ}\right)$. Other limitations on model depiction of LLJ structure and evolution could also be caused by resolution problems or model boundary layer physics that do not capture essential LLJ mechanisms.

Two questions immediately present themselves: (i) Do focused observations at exceptionally high spatial resolution (a few kilometers or better) provide details critical to our operational depiction of the LLJ and (ii) if they do, what is the physical nature of the circulations that are implied? To address them, two aircraft missions during the International $\mathrm{H}_{2} \mathrm{O}$ Experiment (IHOP_2002) during the summer of 2002 were designed to closely observe two separate well-developed LLJs over the Great Plains (primarily Oklahoma and Kansas) with multiple observation platforms. In addition to standard operational platforms (in particular, radiosondes and profilers) to provide the large-scale setting, dropsondes released from the aircraft and a pair of onboard lidar instruments-the High Resolution Doppler Lidar (HRDL) for wind and the differential absorption lidar (DIAL) for moisture-observed the moisture transport in the LLJ at higher resolutions.

With regard to the fundamental question posed previously about the relationship between LLJ evolution and precipitation over the central United States, it is clear that understanding LLJ structure and scales of motion is a first indirect step toward answering that question. Because significant precipitation did not develop within the domain of the 9 June mission, a direct answer relating precipitation and the LLJ via a moisture budget or modeling is not part of this paper.

Section 2 describes the IHOP_2002 LLJ missions and the observational platforms and strategies employed. A practical way of stating the first question above about the utility of high-resolution observations is this: Do convective to mesoscale correlations between moisture and wind fluctuations within the LLJ significantly alter larger (mesoscale to synoptic scale) estimates of LLJ moisture transport? To illustrate this possibility, section 3 compares the qualitative multiscalar structure of the LLJ as revealed in point profiles and within vertical sections across the LLJ of wind, moisture, and resulting moisture transport as observed by multiple observation sets including radiosondes, dropsondes, and simultaneous lidar measurements of moisture and wind. We next focus attention on the bulk properties and effects of scales of motion in section 4 by computing layeraveraged fluxes through sections that bracket the LLJ. From these results, we are able to compute Reynolds averages within the layers, from which we estimate the bulk effect of so-called "prime-prime" terms, interpreted as integrated estimates of the contribution of small-scale (mesoscale to convective scale) circulations to the overall transport. In section 5, we briefly discuss modeling efforts that may eventually be able to describe mesoscale mechanisms that affect the LLJ moisture transport. We summarize our results in section 6 and offer suggestions for further research.

\section{The 9 June LLJ mission: Data, flight strategy, and synoptic setting}

A summary of the IHOP_2002 field campaign, including its myriad of observation platforms, is provided in Weckwerth et al. (2004). The intent of the 9 June mission and another on 3 June was to deploy an array of observation platforms that cascaded from synopticscale operational resolutions to research platforms at much higher resolution. Figures 1-3 provide an overview for the synoptic environment in which the LLJ was embedded on 9 June. The strengthening LLJ over western Texas, Oklahoma, and Kansas coincided with the emergence of a 500-hPa trough from over the Great Basin and Rocky Mountains (Fig. 1). Accompanying the trough is a strong couplet of vertical velocity. The LLJ extends far north to the Dakotas at this time (Fig. 2 ), but its strongest core is associated with a confluence zone near the IHOP_2002 research domain. At the level of the plot in Fig. 2, there is no clear indication of a frontal or other boundary in the fetch of the LLJ. The vertical section of Fig. 3 does show a strongly capped jet layer across the LLJ flight box, especially to its western 


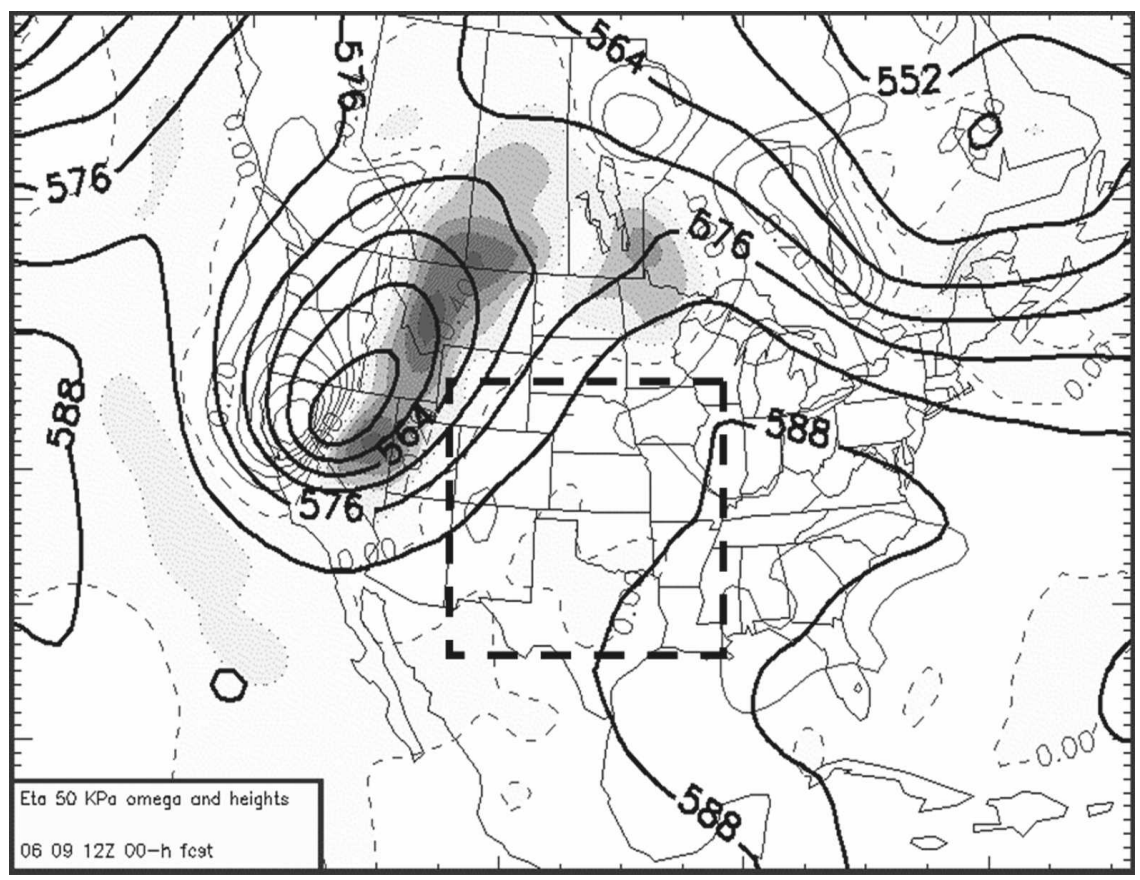

FIG. 1. Geopotential heights at $500 \mathrm{hPa}$ (dam; heavy contours at 6 dam intervals) and omega ( $\mathrm{Pa} \mathrm{s}^{-1}$; light contour intervals at $0.2 \mathrm{~Pa} \mathrm{~s}^{-1}$ ) as analyzed from the operational Eta Model at 1200 UTC 9 Jun 2002. Negative (upward) values of omega are shaded. The heavy dashed rectangle indicates the location of Fig. 2 and the WRF Model domain (described elsewhere in this paper).

side, with downslope warming above it. The region of strongest transport within this layer extends well to the east of the research area and gradually increases in depth toward the east.

Observation platforms deployed on 9 June included the standard operational network observation sets, dropsondes launched at roughly $55-\mathrm{km}$ intervals from research aircraft, and subkilometer-scale measurements by airborne moisture and wind-sensing instrumentation [respectively, the downward-pointing DIAL and the HRDL, both on the German Aerospace Center (DLR) Falcon]. The spacing of dropsonde observations was the best compromise between operational constraints (the speed at which successive sondes could be launched, the time it would take for the sondes to reach the ground to avoid overlapping frequencies, and the number of sondes available for the mission). Two dropsonde aircraft (the DLR Falcon and a Learjet) flew box patterns chosen to bracket the predicted location of the LLJ on 9 June (Fig. 2). The original intent was to have each aircraft complete the full rectangular circuit, refuel, and then repeat the circuit a second time. Instrumentation and aircraft constraints forced adaptations to the original plans, principally because tire problems did not allow the Falcon to fly the second circuit.

The NOAA HRDL was specifically designed for probing small-scale dynamic features in the boundary layer and lower troposphere. Operating in the eye-safe infrared portion of the spectrum at $2.02 \mu \mathrm{m}$, the lidar transmits 2-mJ optical pulses at a rate of $200 \mathrm{~Hz}$. The pulse length of $200 \mathrm{~ns}$ enables resolution of atmospheric features as small as $30 \mathrm{~m}$. Returns are coherently detected and digitally processed to estimate Doppler shift and signal-to-noise ratio (SNR). Typically, 100-200 pulses are accumulated and averaged to for the Doppler and SNR estimates. An absolute precision of the instrument is on the order of $0.05 \mathrm{~ms}^{-1}$; however, precision of an individual measurement is a function of the local aerosol loading. For deployment in IHOP_2002, the HRDL instrument was specifically modified for installation in the Falcon adjacent to the DLR DIAL system.

DIAL is an appropriate technique for the remote sensing of atmospheric trace gases such as water vapor. A DIAL emits short light pulses into the atmosphere at two distinct wavelengths. The online wavelength is tuned to the center of a molecular water vapor absorption line (around $927 \mathrm{~nm}$ in IHOP_2002). The offline wavelength is the reference and contains information about the aerosol load and cloud cover of the probed atmosphere. Combining both online and offline return signals yields the water vapor molecule number density as function of distance from the lidar. The DLR DIAL 


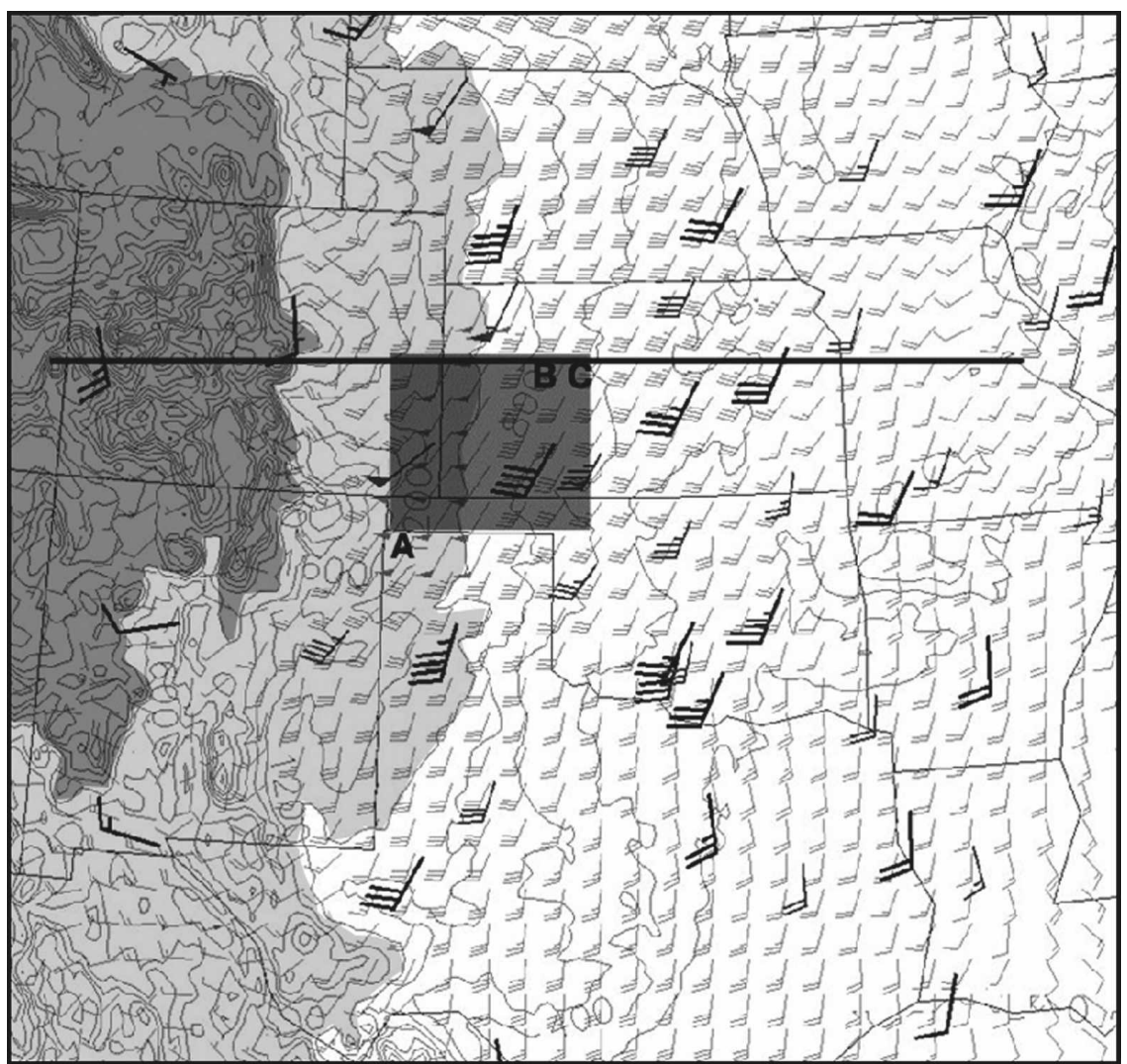

FIG. 2. Observed and analyzed winds at $820 \mathrm{hPa}$ at 1200 UTC 9 Jun 2002 within a region enclosing the LLJ that is the subject of this paper. The geographical location of this domain is indicated by the heavy dashed box in Fig. 1. The largest wind barbs are observations at operational radiosonde observation sites, the medium barbs are at profiler sites, and the smallest gridded winds are at grid points of the WRF model wind analysis at 1300 UTC. Terrain contours are displayed in increments of $200 \mathrm{~m}$, with elevations above $2000 \mathrm{~m}$ darkshaded and elevations 1000-2000 m light-shaded. The gray-shaded rectangular area in Kansas, Oklahoma, and Colorado denotes the aircraft flight box perimeter around which the two research aircraft flew during the 9 Jun LLJ mission. The thick horizontal line that includes the northern leg of the flight path indicates the location of the cross section in Fig. 3. Specific points highlighted along the flight box (denoted A, B, and C) indicate locations of profiles discussed in the text and displayed in subsequent figures.

system transmitter has an average output power of 1.2 $\mathrm{W}$ and is based on an injection-seeded optical parametric oscillator pumped by the second harmonic of a Qswitched, diode-pumped single-mode running neodymium-doped yttrium-aluminum-garnet (Nd:YAG) laser with a repetition rate of $100 \mathrm{~Hz}$. Onboard displays show two-dimensional aerosol backscatter cross sections in real time, which is essential both for direct quality checks and for redirecting aircraft toward interesting atmospheric regions. Dropsonde observations provide air density necessary to convert the water vapor molecule number density measured by DIAL into a mass mixing ratio. The airborne DLR DIAL has successfully participated in numerous international field campaigns, among them IHOP_2002 (Kiemle et al. 2007).
As the observations by the operational network in Figs. 2 and 3 show, the aircraft box on 9 June was well placed to observe the strong LLJ that developed on that day. At slightly lower altitudes than shown on Fig. 2 (closer to the height of maximum winds), the core of the LLJ was more clearly oriented from the southwest side of the south aircraft leg to a point just west of the northeast corner of the box, near the eastern end of the north aircraft leg. Along the southern leg, the jet maximum was more spatially diffuse than it was along the north leg. At its western flank the jet layer itself was quite shallow, even as portrayed by the relatively coarse vertical resolution of Fig. 3. The deeper layer of moisture transport east of the northern flight leg is primarily due to a deeper and moister boundary layer 


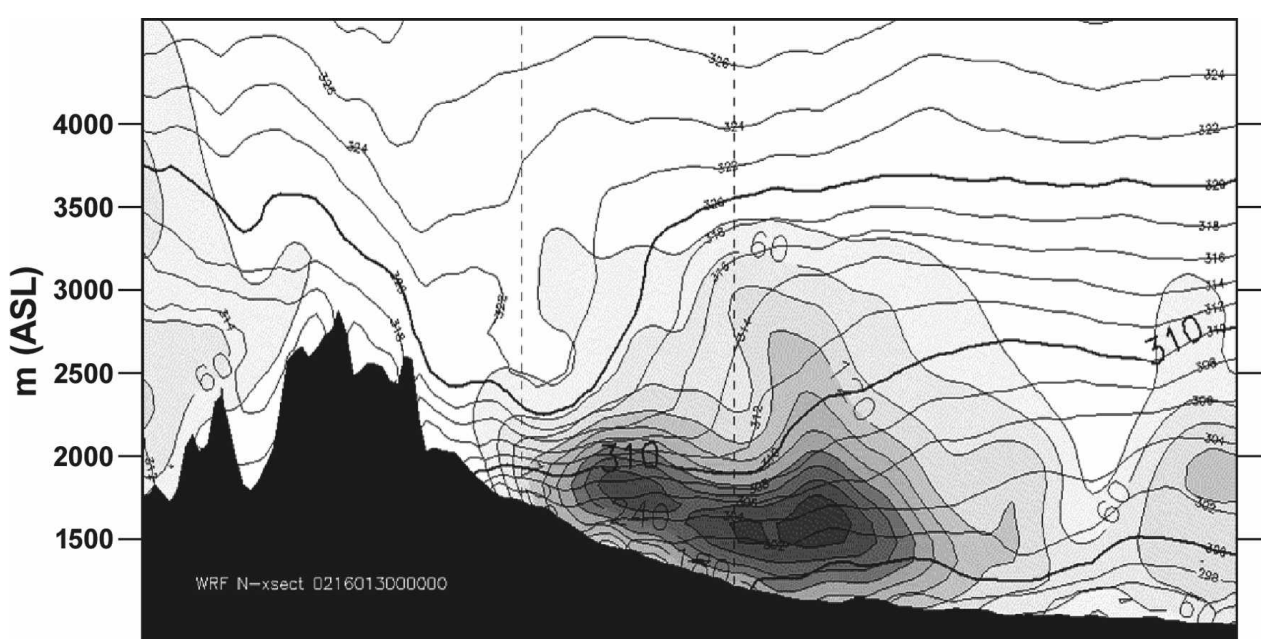

FIG. 3. Potential temperature (K, with contour intervals of $2 \mathrm{~K}$ ) and meridional moisture flux (shaded, $\mathrm{g} \mathrm{kg}^{-1} \mathrm{~m} \mathrm{~s}^{-1}$ and contour intervals of $30 \mathrm{~g} \mathrm{~kg}^{-1} \mathrm{~m} \mathrm{~s}^{-1}$ ) as analyzed in the 12-km WRF Model analysis at 1300 UTC 9 Jun 2002. Meridional moisture flux is computed as $v q$, where $v$ is horizontal meridional wind speed and $q$ is specific humidity. Shown is a west-to-east vertical section that incorporates the northern leg of the rectangular flight track (see Fig. 2). Flight-track end points are indicated by vertical dashed lines.

there rather than an increase in jet wind speed; at most levels, the wind speed core is just west of the eastern end of the northern leg of the flight track. Note that meridional moisture flux is computed here and elsewhere in this paper as $v q$, where $v$ is horizontal meridional wind speed and $q$ is specific humidity.

\section{Multiscale observations}

In Fig. 4, three independently observed profiles of horizontal moisture flux are presented for a location along the perimeter of the research flight box (point A on Fig. 2). All three show a shallow LLJ with a sharp

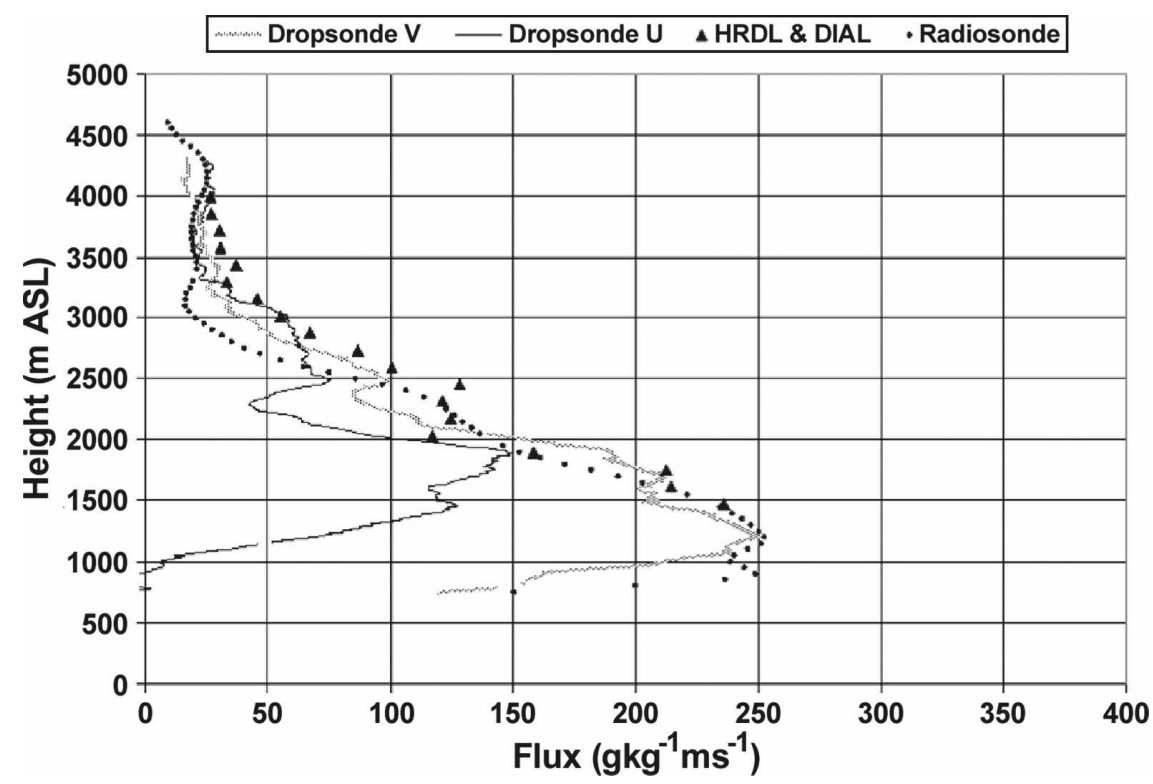

FIG. 4. Comparison of cross-track (i.e., meridional) horizontal moisture transports $\left(\mathrm{g} \mathrm{kg}^{-1}\right.$ $\mathrm{m} \mathrm{s}^{-1}$ ) observed by the instrument platforms indicated at 1251 UTC 9 Jun 2002 near the western end of the southern leg of the flight box (point A in Fig. 2). Dropsonde U (black line) describes the along-track (zonal component) transport observed by dropsondes but not measurable by the DLR Falcon HRDL system. 


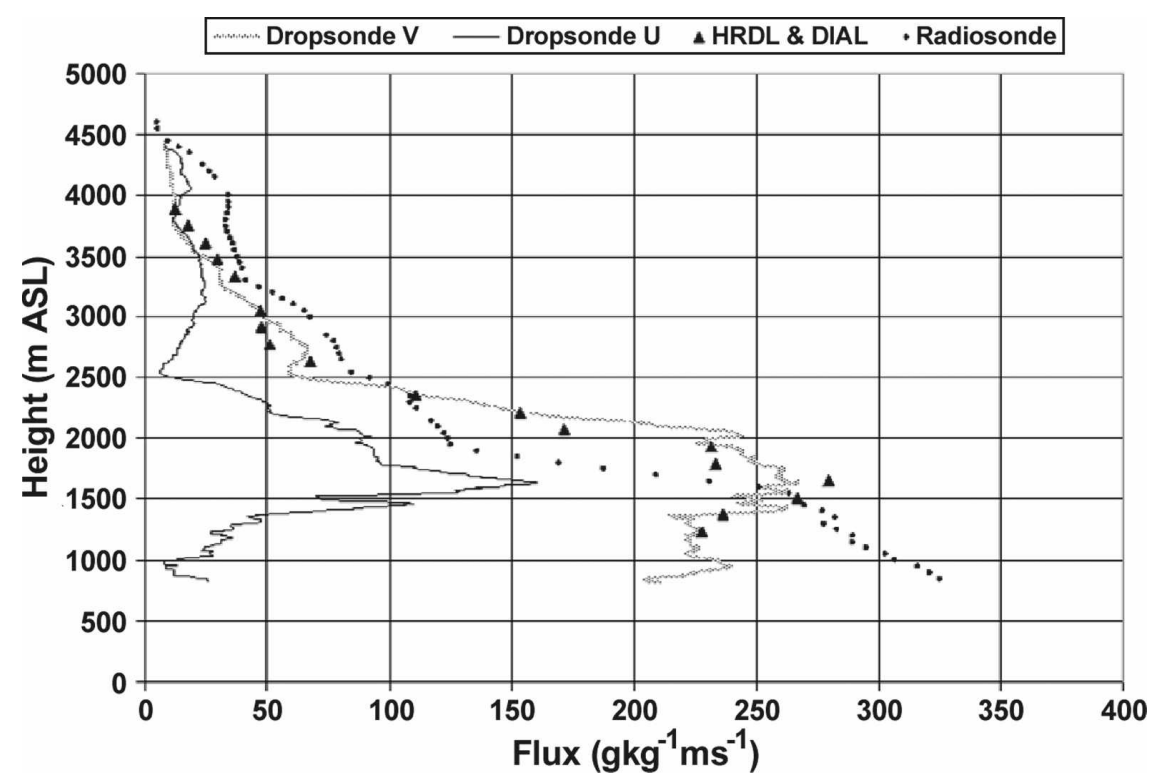

FIG. 5. As in Fig. 4, but for profiles along the northern leg of the flight box (point B in Fig. 2).

transport maximum near $1250 \mathrm{~m}$ MSL (about $500 \mathrm{~m}$ AGL) with rapid gradients above and especially below the core. Clearly, at this location (near the western end of the southern leg) and time (near dawn at 1251 UTC, when the jet can be expected to be less variable and turbulent then it is later during heating-produced mixing; Frisch et al. 1992), all three observation platforms provide remarkably similar pictures of LLJ moisture flux. In the case of the radiosonde observations in Fig. 4 , which are interpolated from neighboring launch sites to the location of the dropsonde profiles, the good agreement reflects the near-synoptic timing of this dropsonde. It is also possible that this particular LLJ was fortuitously well captured by the radiosonde network. Radiosonde profiles at later off-synoptic times and at locations farther from radiosonde launch sites exhibited considerably larger differences from collocated dropsonde and lidar profiles. An example is the set of profiles observed along the northern leg of the flight box later in the morning (Fig. 5). Lidar and dropsonde profiles still agree very well, but the radiosonde analysis badly underestimates the depth of the largemagnitude moisture flux layer and overestimates the flux values very near the surface.

The set of moisture flux cross sections along the northern flight leg in Figs. 6 and 7 also display quite similar jet features. The section in Fig. 6 has been produced from the dropsonde profiles performed along the leg, whereas the section in Fig. 7 is constructed from lidar observations. Apart from the obvious increase in detail in the lidar section, the two sections are similar in jet magnitude and placement along the section. The jet core in both sections, for instance, is located at approximately the same location along the section and at about the same height, the magnitude of the transport there is only slightly larger in the lidar section, and the increasing depth of the jet layer from west to east is very similar. Furthermore, the large undulations along the top of the jet layer in the lidar section are suggested also in the dropsonde section, although the horizontal distance between drops in the latter is marginally adequate to resolve them.

The overall good agreement between the dropsonde flux observations and those produced by the combination of DIAL and HRDL is strong confirmation that both platforms perform well. The performance of the DIAL and HRDL is especially satisfying because IHOP_2002 was the first opportunity to use them in combination to compute fluxes. However, the figures also point out interplatform observation differences with implications for later interpretation of flux computations. For example, the dropsondes have much better vertical resolution, as shown by the spacing of lidar points as compared to the nearly continuous dropsonde profiles. Another difference is emphasized by the large magnitude of the observed flux transverse to the jet core and parallel to the flight path on this leg, denoted as dropsonde $U$ in Figs. 4 and 5 because the leg direction coincided with zonal velocities. Because the HRDL measured only one wind component (the alongjet, north-to-south component on the north and south legs), comparable lidar-based measurements of transport transverse to the jet were not available for comparison with dropsondes. 


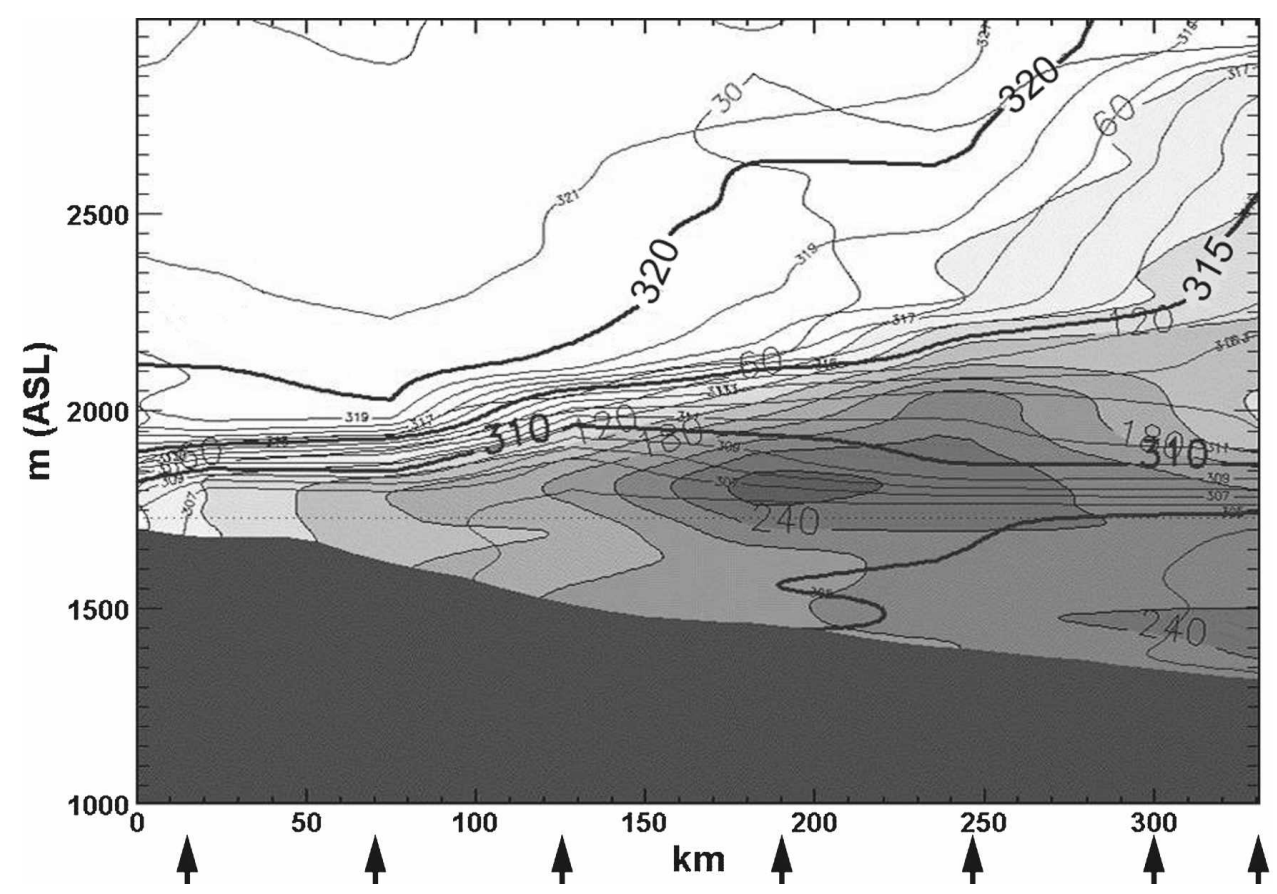

FIG. 6. Potential temperature (solid contours; intervals of $1 \mathrm{~K}$ ) and meridional moisture flux (shaded; intervals of $30 \mathrm{~g} \mathrm{~kg}^{-1} \mathrm{~m} \mathrm{~s}^{-1}$ ) through the northern flight leg during the first circuit of the DLR Falcon ( 1350-1422 UTC 9 Jun 2002). Fluxes are computed and interpolated from dropsonde observations of wind and specific humidity at the positions of the vertical arrows just below the horizontal axis. See Figs. 2 and 3 for orientation and the text for instrumentation description.

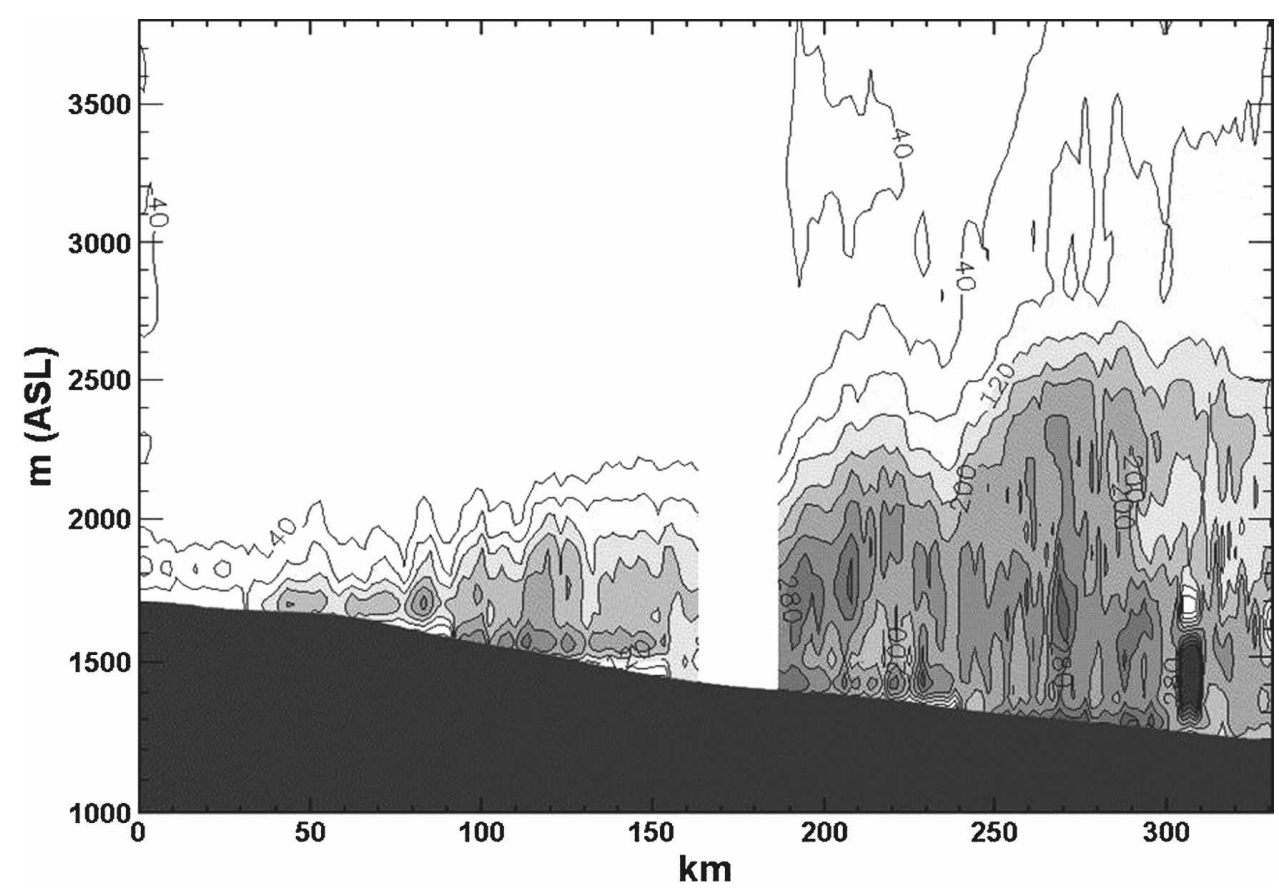

FIG. 7. As in Fig. 6, but for lidar observations of meridional horizontal moisture flux $\left(\mathrm{g} \mathrm{kg}^{-1} \mathrm{~m} \mathrm{~s}^{-1}\right)$. Regions with data dropouts are blank. Distances along the horizontal axis are estimated from aircraft flight speed and times. Contour interval is $40 \mathrm{~g} \mathrm{~kg}^{-1} \mathrm{~m} \mathrm{~s}^{-1}$. The horizontal resolution of the plot is approximately $3 \mathrm{~km}$. 


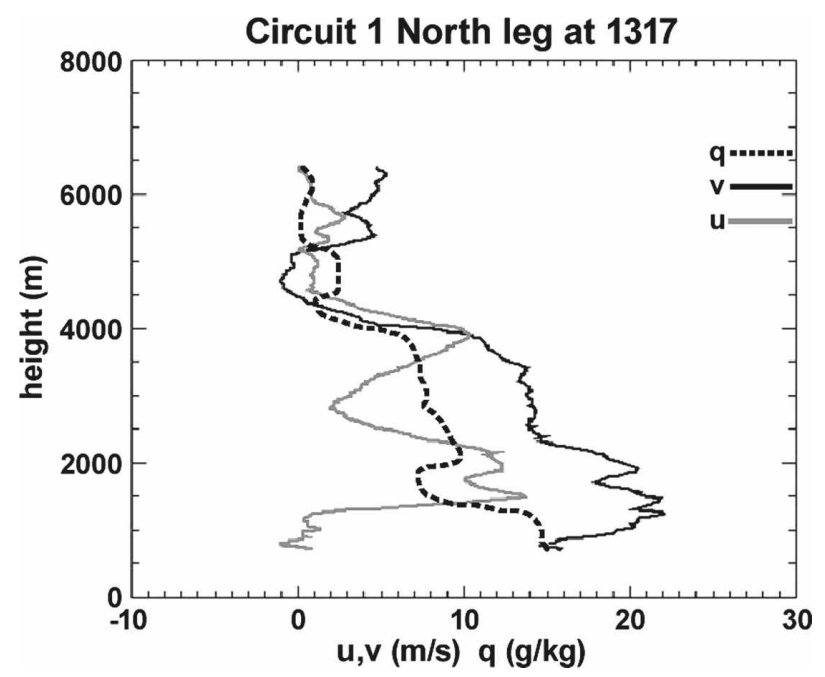

FIG. 8. Zonal $(u)$ and meridional $(v)$ wind components and specific humidity $(q)$ profiles observed by dropsondes launched from the Learjet at the core of the LLJ near the northeast corner of the flight domain on 9 Jun 2002. See Fig. 2, point C, for location. Heights are in meters MSL, and ground level is $\sim 750 \mathrm{~m}$.

Mesoscale structures can reveal themselves either with vertical or horizontal features. Some variability in the vertical profile of moisture flux that could be mesoscale or smaller in origin is evident in Fig. 4, but it is particularly true in profiles observed near the jet core along the north leg. The nature of this variability is illuminated by Fig. 8, which shows the vertical structure in the wind and moisture fields at one such point (point $\mathrm{C}$ on Fig. 2). Clearly, that variability is pronounced in both the wind and moisture fields at this point and time. Because these variations are all very nearly at a point, they could have originated from convection. There were in fact some shallow clouds in the region (see, for instance, the region of cloud contamination between the surface and $1700 \mathrm{~m}$, and just east of $300 \mathrm{~km}$, in the lidar section in Fig. 7), but deep convection at this time in the morning and along a flight track selected to be free of convection is not likely and was not observed. Vertical wavelike features in the transport profile measured by dropsondes are also evident during the second circuit later in the day in the vertical cross section of meridional transport shown in Fig. 9. By this time the layer of strong moisture flux has significantly deepened with the onset of surface heating and consequent turbulent mixing. Concurrently, and presumably also due to mixing within the layer, the intensity of the moisture flux has lessened at the jet core.

Unfortunately, we do not have lidar data during the second circuit to determine if the more clearly apparent vertical features in the dropsonde section at this time are reflected in mesoscale or other horizontal variations. However, shallow vertical structures are suggested in the lidar fluxes observed during the early circuit (Fig. 7), although the vertical scales cannot match those of the more finely resolved dropsonde measurements. In particular, there is an apparent dry layer at

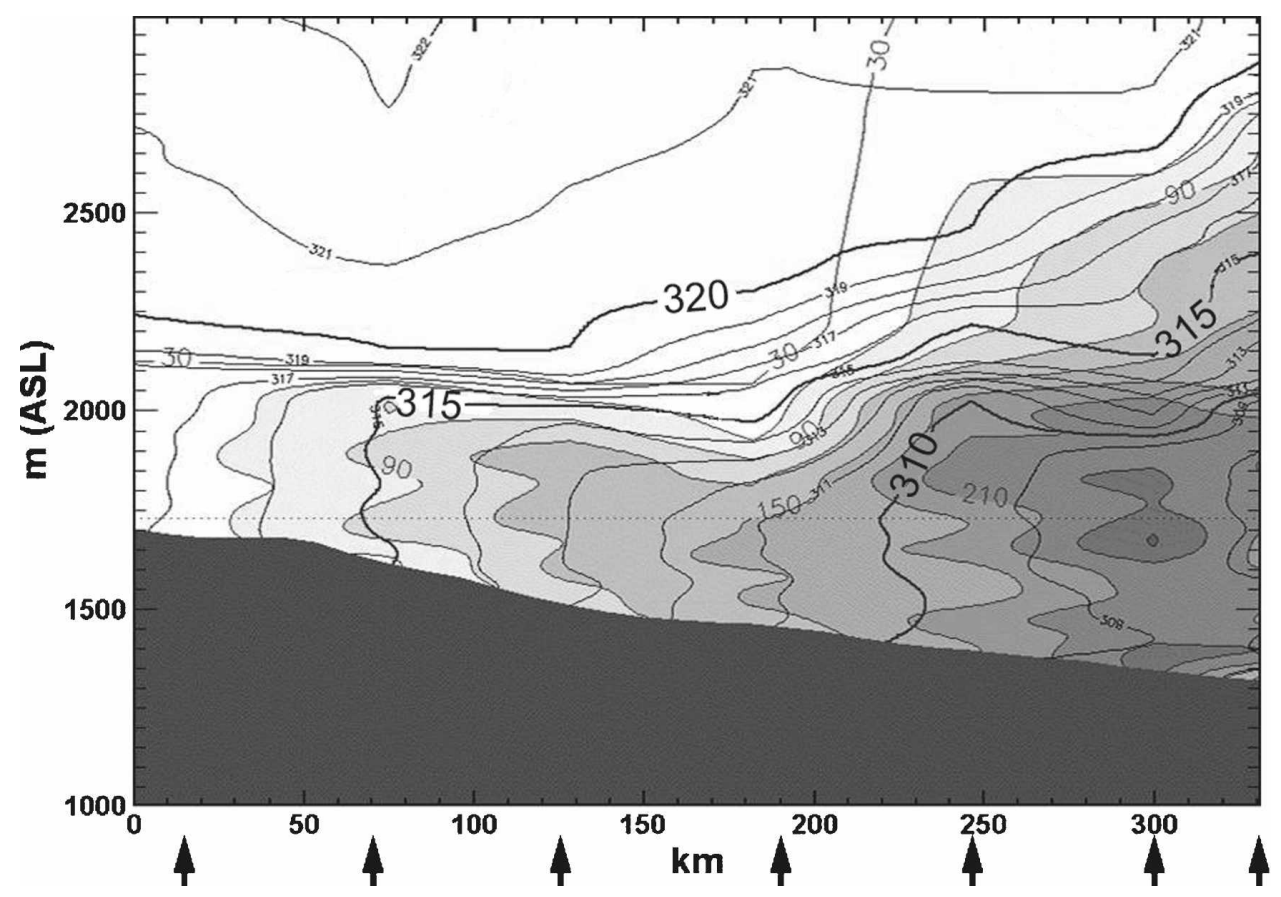

FIG. 9. As in Fig. 6, but for the second circuit of the Learjet ( 1700 UTC 9 Jun 2002). 
$\sim 2000 \mathrm{~m}$ MSL just at the eastern end of the flight leg (reflected in the transport section as a layer of reduced flux). The dropsonde profile of moisture (Fig. 8) at this location also has a pronounced dry layer near this level. Complicating our interpretation of this feature is the fact that the $u$ component of wind measured by the dropsonde shows a spike within the same layer. This large zonal flux is not reflected in HRDL-based observations, which could not measure track-parallel velocities.

The great advantage of the lidar flux measurements is the hugely improved horizontal resolution they offer. In Fig. 7, horizontal variations with dimensions of a few tens of kilometers or less are evident (and confirmed by cospectral analyses; not shown) throughout the LLJ layer. There are also the striking longer wavelike undulations at the top of the LLJ flux layer, particularly in the eastern half of the leg, that were noted previously. Because dropsonde spacing cannot resolve variations of tens of kilometers in the horizontal dimension and can only marginally capture the longer waves, there are no data available to further explain the physical nature of these variations.

Of particular interest to our study is the possibility that these small-scale horizontal features and vertical layers of moisture and wind could correlate strongly enough that operational observations that did not resolve them might significantly underestimate net transport within the LLJ. Figure 10 directly compares point measurements of lidar fluxes with dropsondes at two heights: 2309 m MSL, which is near the top of the LLJ along most of the leg, and $1889 \mathrm{~m} \mathrm{MSL}$, which is deeper inside the LLJ layer. Both suggest that dropsondes do underestimate the total flux because at most (but not all) points along the leg the lidar fluxes are indeed larger. The comparison within the larger-scale undulations east of the section's central point are noteworthy in another respect; at the few points in these undulations where dropsonde measurements and lidar measurements were directly collocated, the two agree surprisingly well. Unfortunately, these collocated points also happened to have fallen at relative lidar flux minima, suggesting that averaging of flux along the section would result in larger lidar estimates. It thus appears that the placement of dropsondes in this part of the leg was singularly unlucky and unlikely to do justice to the transport. This is, of course, the essence of the resolution problem. We will assess the impact of resolution in a more integrated way in the next section.

\section{Bulk estimates of mesoscale horizontal moisture transport}

A more general issue than those taken up in previous sections, but one that is actually more fundamental, is

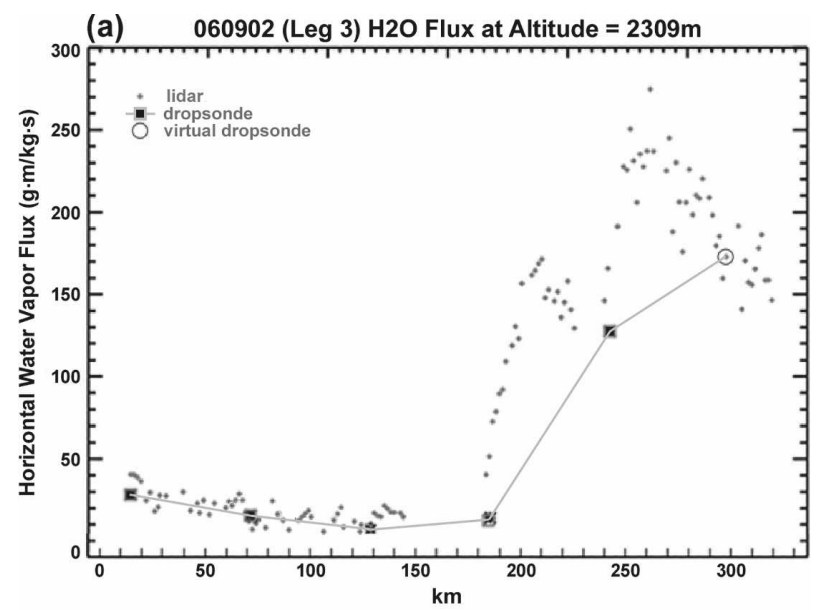

(b) $060902(\operatorname{Leg} 3) \mathrm{H} 2 \mathrm{O}$ Flux at Altitude $=1889 \mathrm{~m}$

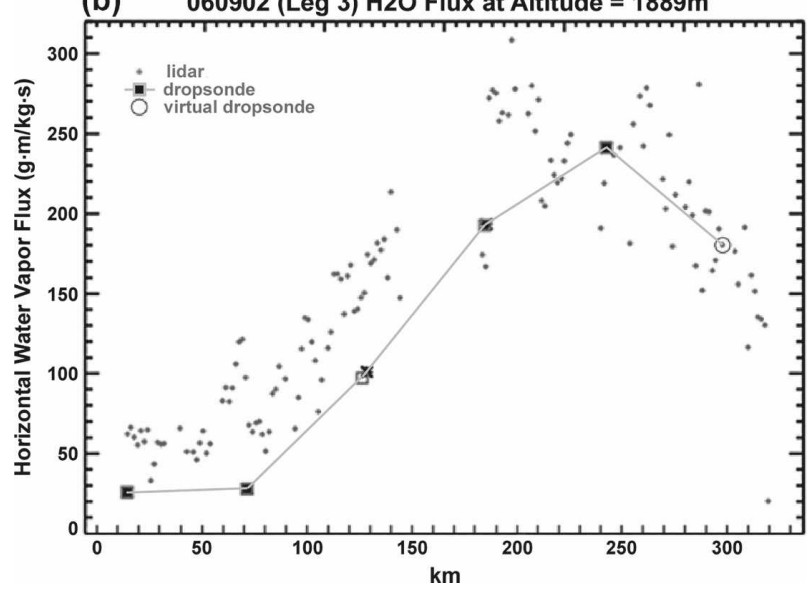

FIG. 10. Comparison of lidar-based (gray points) and dropsonde-based (black squares) meridional moisture flux at two different heights along the northern flight leg flown by the DLR Falcon on 9 Jun 2002. The solid line connecting dropsonde observations is for clarity only and does not indicate other observations between dropsonde symbols. The virtual dropsonde was extrapolated from a dropsonde release near the northeast corner of the flight box but slightly to the south along the eastern leg. Altitudes are MSL.

this: Can we demonstrate that small-scale circulations really do contribute in a significant way to total LLJ transports? One way to address this issue is to apply Reynolds averaging assumptions to estimate the magnitude of the fluxes that are not resolved by a particular set of observations. For horizontal moisture flux determined as the product of wind speed $v$ and specific humidity $q$, we can write the computation as

$$
\overline{v q}=\bar{v} \bar{q}+\overline{v^{\prime} q^{\prime}},
$$

where the overbars indicate averages over a larger scale of interest and the primed terms are differences between the individual observations at smaller scales and the average itself. Stated another way, underlying covariances due to small-scale processes that are not re- 


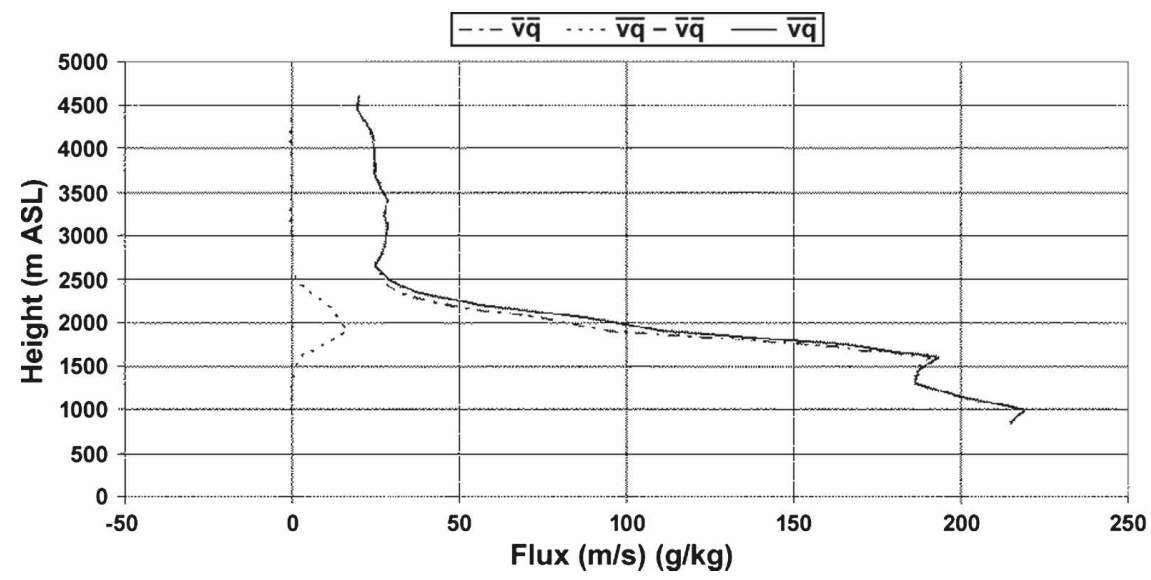

FIG. 11. Components of Reynolds-averaged horizontal moisture flux profiles for the northern flight leg flown by the DLR Falcon at 1350-1422 UTC 9 Jun 2002. The solid curve is the flux averaged over dropsonde locations along the flight leg $(\overline{v q})$; the dashed-dotted curve is the flux computed by multiplying $v$ and $q$ averaged over dropsonde locations along the flight leg $(\bar{v} \bar{q})$; the small dashed curve indicates the differences $(\bar{v} q-\bar{v} \bar{q})$, which we interpret as the contribution by unresolved covariances $\left(\overline{v^{\prime} q^{\prime}}\right)$.

solved by the larger-scale observations can contribute to the total observed flux measured at the larger scale. In the case of dropsonde observations, for instance, we might define the large scale as the average conditions along (say) the north leg of the flight box (somewhat smaller than the effective resolution of the operational profiler network), with the primed terms then constituting the differences between the individual dropsonde observations and the leg average. In this case, the covariances would be due to motions at horizontal scales resolved by observations that are $\sim 55 \mathrm{~km}$ apart, and the large scale would be that resolved by averages at points separated by $\sim 330 \mathrm{~km}$ (the length of the north leg of the flight box). Because the scale separation that results from using dropsondes in this case is marginally adequate, the same set of computations using lidar observations that can be averaged to much smaller horizontal dimensions has also been performed.

The results computed from dropsonde computations are shown in Fig. 11. Except for the top half of the LLJ flux layer, the apparent contribution of dropsonderesolved circulations to larger flight-box-sized averages is small. We speculate that vertical undulations at the top of the LLJ flux layer (similar to those discussed in the previous section) could explain the larger values at the layer top. In Fig. 12, we display the analogous computations using lidar measurements averaged to two scales: one that mimics the resolution of the dropsondes as closely as possible by averaging over $55-\mathrm{km}$ segments and one that utilizes the full capabilities of the lidar horizontal resolution (solid curve). In structure and approximate magnitude, the dropsonde covariance profile and the comparable lidar covariances are similar, with maxima in the upper part of the flux layer. The agreement is heartening because it helps to confirm the validity of both. The full-resolution lidar covariance profile peak, on the other hand, is only slightly larger in magnitude (about 20\%) than the dropsonde-scale results. If accepted literally, this latter result would suggest that along the section, variations of $q$ and $v$ at scales smaller than several tens of kilometers are not highly correlated.

Because the apparent contribution by the correlation term occurs in and just below the top layers of the LLJ, physical mechanisms related to the strong vertical gradients in $v$ and $q$ are suggested. One possible explana-

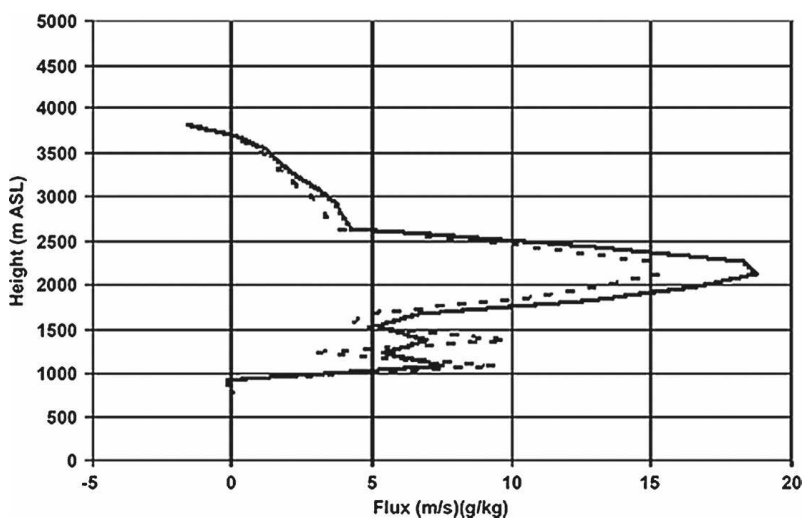

FIG. 12. As in Fig. 11, but for differences $(\bar{v} \bar{q}-\bar{v} \bar{q})$ for DIALHRDL fluxes averaged over $\sim 55-\mathrm{km}$ increments (dropsonde scale; dashed curve) and computed at full resolution (solid curve). See text for explanation. 
tion is that incursions of drier, slower-moving air moving down from above through the shear layer are producing an effect whereby the pockets of anomalously dry air move northward with less velocity than the overall means, resulting in a net positive contribution to moisture flux. These incursions seem likely to be related to the undulations noted previously in the jet layer top.

At this point an important caveat to these results should be noted. Given the flight and measurement constraints previously described, the dropsonde observations are able to ascertain only one component of Reynolds averages, namely the covariance structure between moisture and along-LLJ (but transverse to flight track) velocities along a flight segment that is transverse to the LLJ core. We cannot estimate the potentially large covariances that might have existed between along-jet velocity fluctuations and variations in $q$ in a flight segment that lay in a direction along the jet core. For lidar computations, which observed only the alongjet component $(v)$ on this flight leg, this is also true for the covariances along either possible flight path (transverse to, and along, the LLJ core) between the component of the wind $(u)$ transverse to the jet core and moisture. In retrospect, a set of flight tracks that included segments along the jet in addition to those transverse to it would have been very useful.

Reynolds averaging techniques could be alternatively applied to profiles in an attempt to estimate the contributions by covariances in the vertical. For instance, the larger-scale average could be defined by 200 -m-deep layers, and the primed variables could be the dropsonde observations made every $15 \mathrm{~m}$. Posed in this way, the results would address the questions raised about the apparent layered moisture and wind profiles in Fig. 8. The results of these computations using dropsonde profiles (not shown) indicated no differences and hence no net effect due to covariances between shallow layers of moisture and winds. Because the vertical resolution of the lidar observations is considerably less than that exhibited by dropsonde profiles, defining a large-scale vertical average that preserved minimum scale separation requirements was not possible. Consequently, similar vertical computations using lidar measurements were not attempted.

\section{The search for mesoscale mechanisms: Modeling results}

We have attempted to bridge some of the observational deficiencies revealed in the previous section by using observations as initialization [using the Local Analysis and Prediction System (LAPS) from the Glob- al Systems Division of the Earth System Research Laboratory (ESRL); see Albers 1995, Albers et al. 1996, and Birkenheuer 1999] for retrospective Weather Research and Forecasting (WRF) Model runs. LAPS integrates data from a variety of meteorological observation systems producing analyses on $12-\mathrm{km}$ - (utilized here) and 4-km-resolution grids over the IHOP_2002 experiment area. This includes data from local mesonetworks of surface observing systems, Doppler radars, satellites, wind profilers (404 MHz), and temperature radio acoustic sounding systems (RASS; $915 \mathrm{MHz}$ ), radiometric profilers, and aircraft. These data are incorporated every hour into a three-dimensional grid covering an $1800 \mathrm{~km} \times 1656 \mathrm{~km}$ area for the outer domain (Figs. 1 and 2). These analyses were used to initialize the WRF forecast model during the IHOP_2002 experiment. Research observations (primarily dropsonde measurements of wind, pressure, temperature, and moisture) were included in some parallel runs via a modified telescoping Barnes scheme. The vertical resolution of the LAPS analyses was $25 \mathrm{hPa}$.

During the field experiment, the NOAA Forecast Systems Laboratory (now the Global Systems Division of the ESRL) provided real-time mesoscale numerical model guidance to the IHOP_2002 operations center from multiple advanced modeling systems with the goal of assessing their performance in a quasi-operational environment focused on forecasting the prestorm environment, convective initiation, and quantitative precipitation. Details of this study can be found in Szoke et al. 2004. Retrospectively, the new WRF modeling system (Skamarock et al. 2005) was run in a configuration designed to closely match the fifth-generation Pennsylvania State University-National Center for Atmospheric Research Mesoscale Model (MM5) grid and physics that were used in the real-time campaign to see how its forecast quality would compare using the same input data. The WRF system utilized the following options: a horizontal grid of $151 \times 139$ points with a grid spacing of $12 \mathrm{~km} ; 42$ terrain-following levels using a mass-based vertical coordinate, with higher resolution concentrated in the boundary layer; an advanced thirdorder Runge-Kutta numerical solver with a 50-s integration time step; the Hong-Pan planetary boundary layer parameterization from the National Centers for Environmental Prediction (NCEP) Medium-Range Forecast (MRF) model; and an explicit NCEP five-class microphysical scheme.

Two fundamental modeling questions were addressed: (i) how well could the LAPS-initiated 12-km WRF simulations represent transports in the LLJ and (ii) how great an impact would the inclusion of research observations (e.g., dropsonde profiles along the flight 
(a)

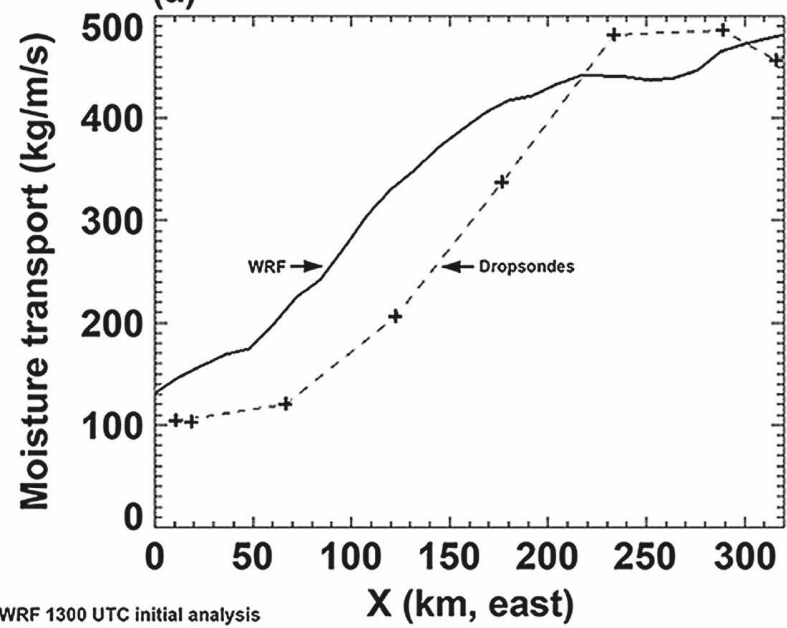

(b)

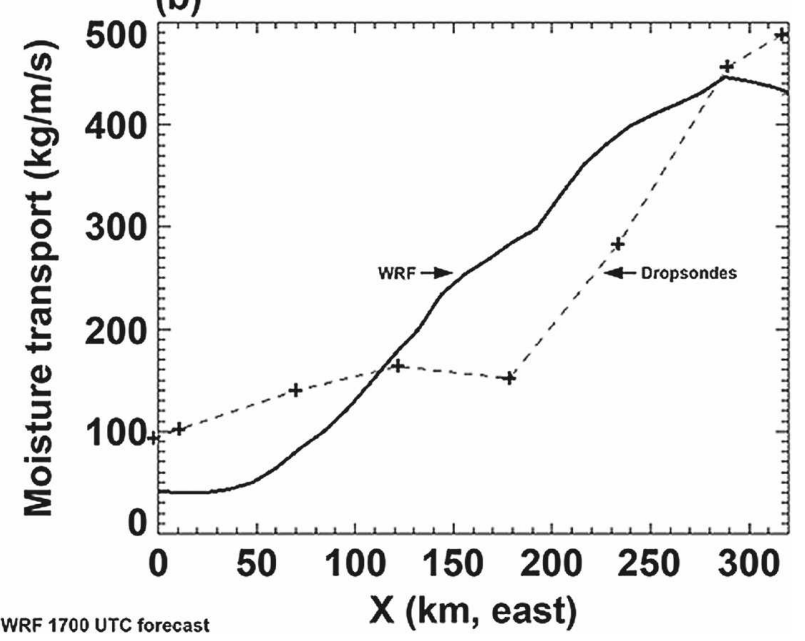

FIG. 13. Vertically integrated (from the surface to $4000 \mathrm{~m}$ ) density-weighted horizontal meridional moisture flux along the north leg of the aircraft flight box as observed by dropsondes (at the locations of the plus signs) and as computed from 12-km WRF Model fields, with conditions centered at (a) 1300 UTC during the first DLR Falcon circuit (WRF initialization) and (b) 1700 UTC during the second circuit of the Learjet aircraft (4-h WRF forecast).

box) have? To generally assess the former, we display initial 12-km WRF winds (small symbols) as the gridded backdrop to the observations (larger symbols) on Fig. 2. Clearly, the model initial fields have captured the general structure of the LLJ. In Fig. 13 we present a comparison of the dropsonde-observed vertically integrated transports along the north flight leg with comparable computations using WRF initialization fields (0-h forecast; Fig. 13a) and 4-h forecast fields (Fig. 13b). Although the initial WRF fields only slightly underestimate the magnitude of peak transport near the eastern end of the leg, it is apparent that the analyses lack some sharpness in horizontal resolution. By $4 \mathrm{~h}$, the WRF Model boundary layer physics have built a jet with strong features, but the forecast still underestimates the sharp horizontal gradient in transport.

The northern-leg section of model-simulated transport in Fig. 14 demonstrates this deficiency clearly. Although the simulation adequately reproduces the general structure of the LLJ, the loss of gradient information is severe throughout the vertical plane. With a feature as shallow and pronounced as the LLJ in the western edge of the experimental domain, the coarse 25 -mb resolution (or $\sim 300 \mathrm{~m}$ within the jet layer) of the LAPS analyses used in this initialization probably could not capture the moisture transport profile with adequate sharpness. Also, as compared with the sections of observed fluxes in Figs. 6 and 7, it is clear that little detail has been generated by the simulations even at the larger dropsonde scales. It is possible that a WRF Model configuration with better boundary layer vertical resolution could produce better detail during the simulation. However, a preliminary sensitivity test (not shown) with a doubling of vertical layers in the WRF Model did not result in significant improvement. Furthermore, several other factors, including boundary layer flux parameterization and horizontal resolution, would have to be studied before a definitive cause could be identified. The series of sensitivity tests necessary to examine these factors was beyond the scope of this paper.

Concerning the impact of dropsonde data when included in the mix of initialization data for the WRF forecasts, parallel initial analyses with and without dropsonde data resulted in negligible differences (Fig. $15)$, and by $4 \mathrm{~h}$ into the WRF forecasts, differences in the jet transport structure between runs were imperceptible. Although it is possible that this particular LLJ was so well captured by the operational observations that the dropsondes were superfluous, we believe that the analyses themselves are relatively insensitive to the existence of extra research data, at least as they are arrayed in this study. To address this issue, it is likely that better vertical resolution in both analyses and models will be necessary before jets like these with such shallow features can be adequately represented. Until then, definitive clarification of the physical nature of mesoscale processes at work in these LLJ cases will have to rely on closer and more imaginative examination of the suite of dropsonde, lidar, and other observations from field experiments like IHOP_2002.

\section{Summary and conclusions}

Drawing on a case study during the IHOP_2002 experiment on 9 June 2002, we have described multiscale 


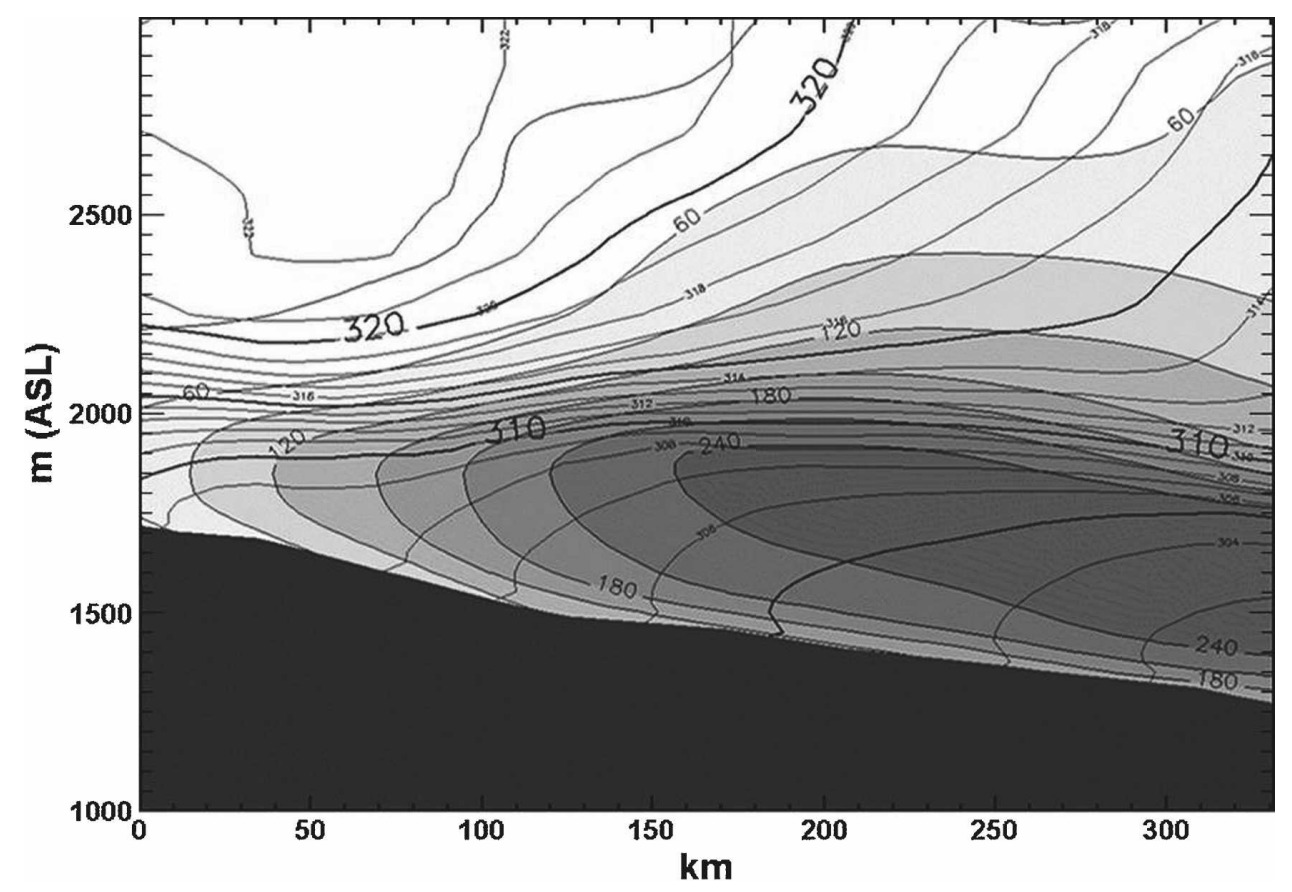

FIG. 14. As in Fig. 6, but for WRF initialization fields at 1300 UTC. Fields displayed are potential temperature (heavy contours; intervals of $5 \mathrm{~K}$ ) and meridional moisture flux (shaded; intervals of $30 \mathrm{~g}$ $\left.\mathrm{kg}^{-1} \mathrm{~m} \mathrm{~s}^{-1}\right)$.

observations from a diverse set of research and operational platforms that typify a strong central plains lowlevel jet. The principal sources of research observations were aircraft-launched dropsondes and airborne DIAL and HRDL lidar observations. These research datasets reveal the structure and the evolution of the water vapor transports within the LLJ during the early morning at unprecedented detail, and the larger-scale operational observations provide the background environment in which the jet transports exist. In particular, the lidar-based and dropsonde-based observations seemed to operate quite successfully, simultaneously showing very similar structure in the transport fields when the two observation sets were in close proximity. When compared over a leg of the flight box, the lidar flux observations were often more than $25 \%$ larger than interpolated dropsonde values. As expected, radiosonde observations displaced in time and space from the research profiles show lesser agreement.

Bulk estimates of moisture and velocity (Reynolds averages), which we interpret as proxy estimates for small-scale transports, show strongest contributions within the layer of sharp moisture and momentum gradients situated in the upper layers of the LLJ. We suggest that the contributing mechanism to positively correlated velocity and moisture ( $v$ and $q$, respectively) in this layer may be masses of drier, lower-momentum air from above that have moved into the layers below. As revealed using the aircraft dropsonde data with spatial separation of $\sim 50 \mathrm{~km}$, these contributions due to $v$ and $q$ covariances are not large, averaging about $10 \%-15 \%$ of transports by the larger scales (as described by the box width, about $350 \mathrm{~km}$ ). Cross sections of actual transport observations along the northern leg of the aircraft flight (Figs. 5-7) suggest that the motions producing these mesoscale contributions appeared as undulations along the top of the LLJ layer. When computed with lidar data with finer horizontal resolution, the Reynolds averages were only slightly larger, suggesting that $v$ and $q$ covariances at smaller scales of motion than those analyzed by the dropsonde observations were present but were relatively insignificant. However, there is an important caveat to these bulk findings due to the observational limitations of the lidar and dropsonde platforms: only along-track variations of velocity and hence moisture transport could be measured, and lidar could only observe one component of transport, that transverse to the aircraft track (the alongjet component). A great addition to future field studies of the LLJ would be estimates of both along-track and transverse variations of moisture transport, even if these observations could not be made simultaneously.

Although high-resolution (12 km) WRF Model simulations of the LLJ for this case were generally success- 
(a) NOAA/GSD LAPS

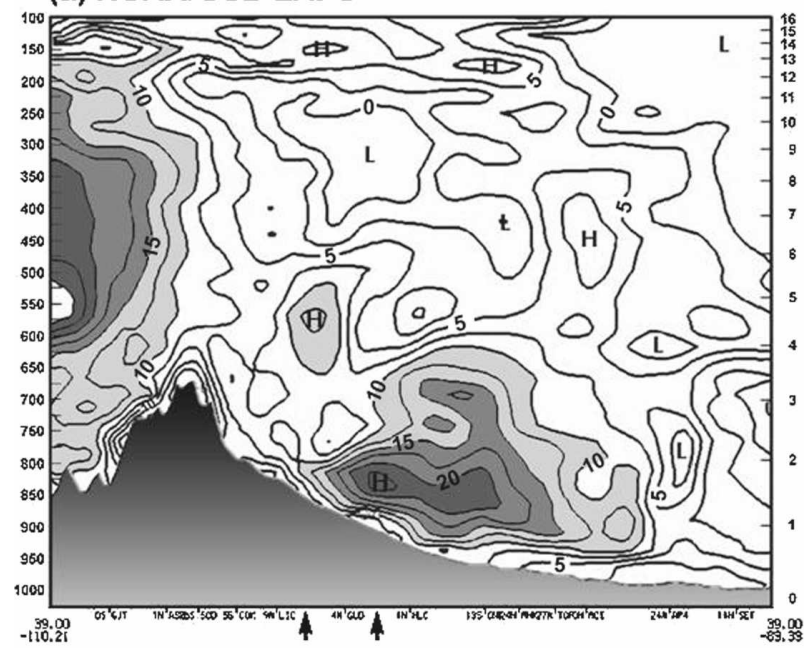

(b) NOAA/GSD LAPS

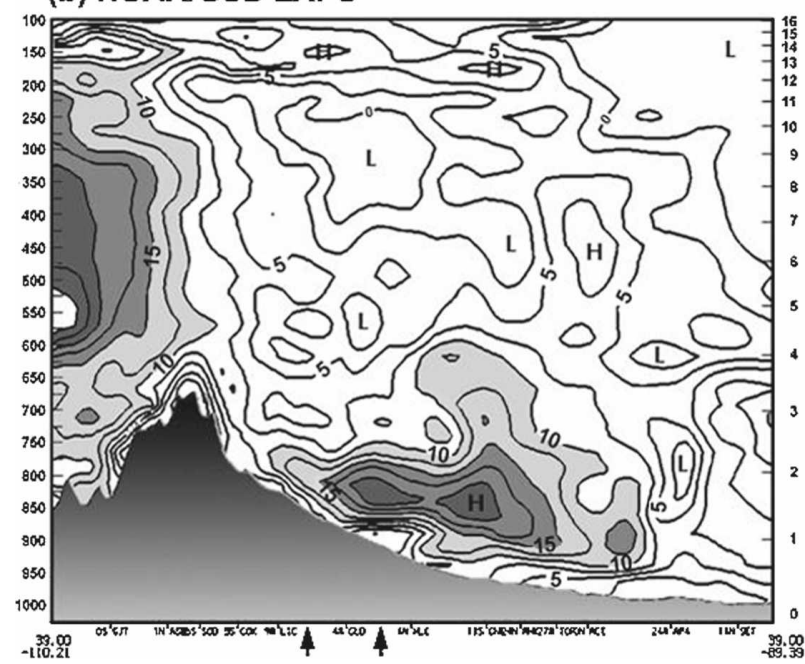

FIG. 15. Meridional velocity $(v)$ at 1300 UTC 9 Jun 2002 along the latitude of the northern leg of the research flight box as analyzed by LAPS (a) with and (b) without ingest of dropsonde observations. Wind speeds are in meters per second with contour intervals of $2.5 \mathrm{~m} \mathrm{~s}^{-1}$. Height units are hectopascals along the left vertical axes and kilometers along the right vertical axes. Arrows under sections mark the endpoints of the northern flight leg.

ful, they were not able to capture the extremely sharp, shallow nature of this LLJ, particularly at its western flank. We speculate that the vertical resolution of models and their initialization fields must be better in order to improve LLJ simulations of moisture transports in the LLJ. However, future detailed sensitivity studies will be needed to confirm this possibility. Because the LLJ cases studied in IHOP_2002 were not associated with rainfall (observed or simulated) within the observation domain, we were unable to determine if the LAPS-WRF assimilation of dropsonde observations had an important effect on precipitation forecasts.
Acknowledgments. We thank Chris Anderson, Isidora Jankov, and Ann Reiser for discussions and for their reviews of this paper. John Osborn and Will von Dauster provided excellent help with figures. Two anonymous reviewers also had valuable suggestions that improved the presentation of our results. Some of the work described here was supported by a grant from the U.S. Weather Research Program.

\section{REFERENCES}

Albers, S., 1995: The LAPS wind analysis. Wea. Forecasting, 10, 342-352.

—, J. A. McGinley, D. Birkenheuer, and J. Smart, 1996: The Local Analysis and Prediction System (LAPS): Analyses of clouds, precipitation, and temperature. Wea. Forecasting, 11, 273-287.

Anderson, C. J., and R. W. Arritt, 1998: Mesoscale convective complexes and persistent elongated convective systems over the United States during 1992 and 1993. Mon. Wea. Rev., 126, $578-599$.

— and — 2001: Representation of summertime low-level jets in the central United States by the NCEP-NCAR reanalysis. J. Climate, 14, 234-247.

Augustine, J. A., and F. Caracena, 1994: Lower-tropospheric precursors to nocturnal MCS development over the central United States. Wea. Forecasting, 9, 116-135.

Banta, R. M., R. K. Newsom, J. K. Lundquist, Y. L. Pichugina, R. L. Coulter, and L. J. Mahrt, 2002: Nocturnal low-level jet characteristics over Kansas during CASES-99. Bound.-Layer Meteor., 105, 221-252.

Birkenheuer, D., 1999: The effect of using digital satellite imagery in the LAPS moisture analysis. Wea. Forecasting, 14, 782-788.

Bonner, W. D., 1968: Climatology of the low-level jet. Mon. Wea. Rev., 96, 833-850.

Daniel, C. J., R. W. Arrit, and C. J. Anderson, 1999: Accuracy of 404-MHz radar profilers for detection of low-level jets over the central United States. J. Appl. Meteor., 38, 1391-1396.

Frisch, A. S., B. W. Orr, and B. E. Martner, 1992: Doppler radar observations of the development of a boundary layer nocturnal jet. Mon. Wea. Rev., 120, 3-16.

Fritsch, J. M., R. J. Kane, and C. R. Chelius, 1986: The contribution of mesoscale convective weather systems to the warmseason precipitation in the United States. J. Climate Appl. Meteor., 25, 1333-1345.

Higgins, R. W., K. C. Mo, and S. D. Schubert, 1996: The moisture budget of the central United States in spring as evaluated in the NCEP-NCAR and the NASA-DAO reanalyses. Mon. Wea. Rev., 124, 939-963.

— Y Y. Yao, E. S. Yarosh, J. E. Janowiak, and K. C. Mo, 1997: Influence of the Great Plains low-level jet on summertime precipitation and moisture transport over the central United States. J. Climate, 10, 481-507.

Kiemle, C., and Coauthors, 2007: Latent heat flux profiles from collocated airborne water vapor and wind lidars during IHOP_2002. J. Atmos. Oceanic Technol., 24, 627-639.

Maddox, R. A., 1983: Large-scale meteorological conditions associated with midlatitude, mesoscale convective complexes. Mon. Wea. Rev., 111, 1475-1493.

Mitchell, M. J., R. W. Arritt, and K. Labas, 1995: A climatology of 
the warm season Great Plains low-level jet using wind profiler observations. Wea. Forecasting, 10, 576-591.

Ralph, F. M., P. J. Neiman, and R. Rotunno, 2005: Dropsonde observations in low-level jets over the northeastern Pacific Ocean from CALJET-1998 and PACJET-2001: Mean vertical-profile and atmospheric-river characteristics. Mon. Wea. Rev., 133, 889-910.

Skamarock, W. C., J. B. Klemp, J. Dudhia, D. O. Gill, D. M. Barker, W. Wang, and J. G. Powers, 2005: A description of the advanced research WRF version 2. NCAR Tech. Note NCAR/TN-468+STR, 88 pp.

Stensrud, D. J., 1996: Importance of low-level jets to climate: A review. J. Climate, 9, 1698-1711.
Szoke, E., J. Brown, and B. Shaw, 2004: Examination of the performance of several mesoscale models for convective forecasting during IHOP. Preprints, 20th Conf. on Weather Analysis and Forecasting and 16th Conf. on Numerical Weather Prediction, Seattle, WA, Amer. Meteor. Soc., J13.6. [Available online at http://ams.confex.com/ams/pdfpapers/ 68930.pdf.]

Weckwerth, T. M., and Coauthors, 2004: An overview of the International H2O Project (IHOP 2002) and some preliminary highlights. Bull. Amer. Meteor. Soc., 85, 253-277.

Whiteman, C. D., X. Bian, and S. Zhong, 1997: Low-level jet climatology from enhanced rawinsonde observations at a site in the southern Great Plains. J. Appl. Meteor., 36, 1363-1376. 